\title{
IMPACT OF ENVIRONMENTAL UNCERTAINTY AND CONTRACTUAL EMBEDDEDNESS ON SUPPLIER'S SALES PROBABILITY
}

\begin{abstract}
Existing literature offers limited knowledge about online markets that consist of open contractual and supply networks. Online markets allow consumers to develop their supply chains by choosing suppliers from the open contractual network. Suppliers' contractual embeddedness (SCE), which is how they are contracted with each other, may influence their sales probability in online markets. However, SCE is conceptually vague because literature posits both linear and nonlinear effects of embeddedness on performance mostly based on subjective measures. Also, suppliers change their contracts in online markets to adapt to environmental uncertainty over time, but this remains poorly understood in the literature. Hence, this study explores how the environmental uncertainty dimensions of dynamism, munificence and complexity and objective measures of SCE such as degree and closeness centralities impact the supplier's sales probability by mainly invoking Complex Adaptive System theory and Social Network theories. Applying panel logit regression model to Australian-based Open Food Network data from 2012 to 2016, this study empirically validates that SCE generally improves the supplier's sales probability and environmental uncertainty dimensions moderate that relationship. Network diagrams illustrate the local optimisation behaviour of network clusters and how they evolve into different network patterns over time.
\end{abstract}

Key Words: Supplier's Contractual Embeddedness, Environmental Uncertainty, Social Network Analysis, Complex Adaptive System, Sales Probability 


\section{INTRODUCTION}

In complex adaptive system (CAS) view, a supply network emerges over time and coevolves with environment rather than being a purposeful design by a single firm (Choi, Dooley and Rungtusanatham, 2001; Li, Yang, Sun, Ji and Feng, 2010; Nair, Yan, Ro, Oke, Chiles and Lee, 2016; Park, Bellamy and Basole, 2018). The open contractual and supply networks that coexist in online markets have received little research interest. The open contractual network is where any supplier can register and connect to each other based on their mutual trust in online markets. The supply network is the collection of consumer designed supply chains choosing the suppliers of the open contractual network in each order cycle. However, literature does not explain how consumers develop supply network using the open contractual network in online markets, and suppliers increase sales probability and adapt to environmental uncertainty.

SCE is how a supplier link to each other in the open contractual network and might improve the supplier's economic outcomes such as sales probability in the supply network. Relative positions of suppliers in a network influence both their strategy and behaviour (Borgatti and $\mathrm{Li}$, 2009). For instance, in online markets, consumers usually consider shipping distances and how suppliers organise themselves to offer a variety of products before placing orders. Hence, consumers bear SCE in mind when developing their supply chains and eventually to derive the supply network of the online market. However, scholars have contradicting beliefs about SCE because some believe an inverted $\mathrm{U}$ shape relationship between embeddedness and performance while others believe that embeddedness generally improves performance (Kim, Chen and Linderman, 2015; Kim, Choi, Yan and Dooley, 2011; Uzzi, 1996). Although scholars commonly use subjective measures to inform supplier's embeddedness because of difficulties in network data collection (Choi and Kim, 2008; Kim, 2014; Uzzi, 1996), now, the social network analysis (SNA) 
matrices are widely available to objectively inform SCE using different centralities (Borgatti and Li, 2009; Kim et al., 2011; Kim et al., 2015; Kito, Brintrup and New, 2014).

Further, online markets often promote agile strategies in the open contractual network to respond to environmental uncertainty (Gligor, Esmark and Holcomb, 2015; Pagell and Krause, 2004). The supplier firms embedded in the open contractual network take longer to develop regular routines in the supply network when environments are highly uncertain, and this disrupts their ability to pursue price or quality-based competition (Gligor 2018; Kim et al., 2011; Terjesen, Patel and Covin, 2011). Environmental uncertainty is another factor influencing the supplier's sales probability in the supply network that has received less attention in the prior literature.

To address these concerns in the literature, this study explores the longitudinal effects of SCE informed by degree and closeness centralities and environmental uncertainty dimensions of dynamism, munificence and complexity, on supplier's sales probability in the supply network. In this research context, the degree centrality is the total number of contracts a supplier holds, and the closeness centrality is the minimum number of contracts that a supplier needs to reach all the other suppliers in the open contractual network (Borgatti and Li, 2009; Kim et al., 2011). This study employs the CAS theory as a theoretical lens to recognise the interplay between environmental uncertainty and SCE dimensions (Choi et al., 2001; Park et al., 2018). This study also relies on the SNA technique to derive centrality measures of SCE by developing open contractual and supply network diagrams from 2012 to 2016 (Freeman, 1979; Kim et al., 2011) and they illustrate how coexisting networks evolve to respond to environmental uncertainty dimensions. The study addresses the following research question:

- How do environmental uncertainty and supplier's contractual embeddedness impact the supplier's sales probability in the supply network, over time? 
Empirical context is the Australian-based Open Food Network (OFN) that recently emerged to match the local food surpluses with market demands via an electronic marketplace (OFN, 2018). OFN's open contractual network consists of small to medium scale farmers and food hubs who register their profiles including product and shipping options on the OFN. When a consumer makes an online order, the consumer designs its food supply chain by picking preferred suppliers from the open contractual network for each item. The chosen food suppliers become nodes of the supply network. The open contractual and supply networks of OFN are ideal examples of a CAS because the networks emerge over time into coherent forms and adapt and organise themselves without any single business deliberately managing them (Choi et al., 2001; Holland, 1992; Pathak, Day, Nair, Sawaya and Kristal, 2007). Thus, the study can use OFN to analyse the impact of environmental uncertainty and SCE on the supplier's sales probability in the supply network and how the two networks evolve, over time. The study uses panel data of food suppliers registered to the OFN from 2012 to 2016.

This study makes several contributions to the literature. The study explores the gaps in the literature by applying CAS to elucidate how the supply network emerges as a derivative of the open contractual network. This study also objectively measures the concept of SCE using the degree and closeness centralities than the widely used subjective measures. The results reveal that greater SCE generally improves a supplier's sales probability in the supply network context contradicting the belief about non-linear effects of the embeddedness on performance. This study graphically unveils how the open contractual and supply networks evolve from 2012 to 2016 using the SNA. Geographically remote network clusters evolve into different network patterns such as scale-free, block diagonal and centralised and exhibit the local optimisation behaviour of satisfying the local requirements rather than those of OFN. This study further discloses that environmental uncertainty dimensions moderate the relationship between SCE and the supplier's sales probability. The 
association between a supplier's degree centrality and its sales probability continues to increase in both dynamic and complex environments. The association between a supplier's closeness centrality and its sales probability increases in munificent environments while that decreases in dynamic environments. This study integrates the CAS theory, SNA and the literature of environmental uncertainty, supply chain and performance.

\section{LITERATURE REVIEW}

\section{Complex Adaptive System Theory}

Supply network stream first adopts the CAS perspective to gain insights into central issues of the domain (Pathak et al., 2007). A CAS consists of a large number of non-additively interacting agents governed by a set of rules (Gell-Mann, 1994; Holland, 1992, 2002). Choi et al. (2001) explains how a supply network coevolves with environmental dimensions of dynamism and rugged landscapes through CAS lens. Later, Surana, Kumara, Greaves and Raghavan (2005) propose various techniques to model the supply network as a CAS based on nonlinear dynamics, statistical physics and information theory. Then, Pathak et al. (2007) summarise the past and potential CAS related supply network researches and emphasise on CAS constructs, such as dynamism, complexity, evolutionary trajectories and adaptivity.

Simulation-based studies strengthen the CAS adoption to the supply network issues. Pathak, Dilts and Biswas (2007) investigate the evolution of topological structures that supply networks may form by using 80 years of data of the US automobile industry to classify rules that evoke different environmental and firms' behaviours. Li et al. (2010) run both simulation and a case study analyses to validate evolutionary complexities and collaboration mechanisms of the supply network. External environment has a long-term impact on network evolution, while a firm's 
internal factors of cost and quality exert an immediate influence (Li et al., 2010). Nair and Vidal (2011) use the agent-based model to verify the associations between a network's topology and its robustness in the presence of random failures and targeted attacks.

Few qualitative and empirical studies develop CAS related concepts in supply network area. Choi and Hong (2002) map three different assembly line supply networks to recognise the structural dimensions of formalisation, centralisation and complexity. Cost is the overarching force that shapes these structures, and they affect one another progressively. Wu and Choi (2005) identify five archetypes of supplier-supplier relationships that lead to implications of buyer's sourcing strategy. Pathak, Wu and Johnston (2014) explore the coexisting dynamics of cooperation and competition (co-opetition) in a complex supply network, and they develop four network archetypes taking a configurational approach. Nair et al. (2016) use a process model to indicate how the dominant buying firms keep environmental innovations under their control and then proliferate in the supply network over time.

\section{Open Food Network as a Complex Adaptive System}

OFN is a project of the Open Food Foundation, a non-profit, registered charity established in 2012 to develop, accumulate, and protect open source knowledge, code, applications, and platforms for fair and sustainable food systems (OFN, 2018). It is a technology-based innovation that provides greater market access to suppliers and consumers at a premium price (Kurnia, Rahim, Hill, Larsen, Braun, Samson and Singh, 2017; OFN, 2018). OFN, which is an alternative commodity market to achieve the food suppliers' economies of scale, started with 34 registered food suppliers in 2012 and grew to 1876 by 2016 . The OFN does not impose any barriers to network entry for suppliers (producers and food hubs), and they can connect to each other based on their mutual understanding which in turn develop the open contractual network of OFN. However, a supplier becomes a part 
of the supply network if only a consumer places an order with the supplier. Consumers can request a suitable distribution from food hubs, either a pickup or delivery to the doorstep. Overall, OFN is a successful business model that deploys coordination strategies without a controller and leads to adaptive behaviour of open contractual and supply networks (Choi et al., 2001; OFN, 2018). Hence, these two networks are CASs.

\section{Supplier's Contractual Embeddedness (SCE)}

Suppliers of the open contractual network make open contracts with each other without any barriers to entry or exit from the contract. Sometimes a supplier firm can make contracts with extended suppliers, and then direct immediate suppliers to buy from them (Choi and Hong, 2002; Kim et al., 2011). A firm's central position in a contractual network (SCE) has a significant impact on its and other suppliers' behaviours and performances (Kim et al., 2011). In the same vein, Burt (1992) asserts that the structural dimension of a network predicts and controls a firm's access to other firms' knowledge, resources and information (Bellamy, Ghosh and Hora, 2014; Borgatti and Halgin, 2011; Nahapiet and Ghoshal, 1998).

The four centralities of degree, eigenvector, closeness, and betweenness measure the supplier's centralisation of a network in different aspects (Borgatti and Li, 2009; Freeman, 1979). Degree centrality is the number of firms connected to a specific firm (Freeman, 1979; Kim et al., 2011). Eigenvector centrality is an extension of degree centrality and measures how well a firm is connected to the other well-connected firms in a network (Bonacich and Lloyd, 2001; Borgatti and $\mathrm{Li}, 2009)$. Closeness centrality is the minimum number of steps to reach from an origin firm to all the other firms in a network (Kim et al., 2011). Betweenness centrality is the firm's probability of being the direct route between another two firms in a network (Borgatti and Li, 2009; Freeman, 1979). Degree and closeness centralities are most appropriate to inform the SCE Since OFN 
consists of geographically isolated clusters and aims to deliver products with minimum distance, time, logistics costs, and emissions.

\section{Environmental Uncertainty}

Business environment consists of multiple forces which are outside a firm but can influence a firm's ability to prosper and survive (Li et al., 2010; Pathak et al., 2007). Environment is modelled with institutional constraints such as economy, law and market structure and operational constraints such as demand and supply (Li et al., 2010: Pathak et al., 2007). Prior literature also informs the environmental uncertainty as a multi-dimensional construct, with the most commonly recognised dimensions being dynamism, munificence, and complexity (Dess and Beard, 1984; Gligor et al., 2015). Dynamism refers to the unpredictability of environmental change and the fluctuations in demand and sales, while munificence reflects the degree to which environmental resources are supportive of sustained growth of a firm in an industry (Anderson and Tushman, 2001; Dess and Beard, 1984; Gligor et al., 2015). Complexity deals with heterogeneity and range of a firm's activities, such as industry concentration and geographic dispersion (Child, 1972; Gligor, 2018; Keats and Hitt, 1988).

The digital markets change the way supplier firms used to operate and promote networklevel decision-making more than isolated actions (Azadegan, Patel, Zangoueinezhad and Linderman, 2013; Park et al., 2018). Consequently, recent findings obscure the direct effects of the environmental uncertainty dimensions, while they appear to strongly moderate the supply chain strategies, to shape performance (Eroglu and Hofer; 2014; Gligor, 2018; Pagell and Krause, 2004). For instance, networks with agile structures gain a competitive advantage in the industries that require rapid responses to market and technological changes (Azadegan et al., 2013; Gligor et al., 2015; Pagell and Krause, 2004). In online markets, suppliers commonly practise flexible strategies 
such as shorter order cycles and offer affordable and quality product ranges to adapt to environmental uncertainty (Gligor, 2018; OFN, 2018). Hence, environmental uncertainty dimensions are more likely to moderate the relationship between SCE and supplier's sales probability.

\section{Supplier's Sales Probability}

Sales are one of the key supply chain performance outputs that align with supplier strategies and customer values (Beamon, 1999). In the OFN, a food supplier earns sales in the supply network if only a consumer makes an order to the supplier. Suppliers can ensure return sales by offering a reliable, quality and affordable product range to satisfy consumers. For that, suppliers need to connect to trustworthy extended suppliers of the open contractual network of OFN. They can collaboratively raise brand awareness among local customers through product differentiation, branding, and regional identity (Kurnia et al., 2017). The suppliers' survival in an electronic market, such as OFN, depends on how many online sales they make via the consumer-designed supply network. In this context, if a supplier in the open contractual network gets an order from consumers in an order cycle, its sales probability is one, otherwise zero.

\section{Conceptual Model}

Insert Figure 1 about here

Figure 1 shows the proposed relationships among environmental uncertainty, SCE, and supplier's sales probability in the supply network. This study is the first attempt to conceptualise and empirically test the simultaneous evolution of open contractual and supply networks grown out of a single system, the OFN, in an internet-enabled market platform in response to environmental uncertainty. 


\section{HYPOTHESES DEVELOPMENT}

\section{Supplier's Contractual Embeddedness and Sales Probability}

Open contractual network of OFN exhibits complex multi-scale behaviour among suppliers since a variety of food producers, restaurants, and food hubs evolves and self-organises through a complex interplay of network structure and function (Choi et al., 2001; Dooley,1997; Surana et al., 2005). Changing market trends persuade open contractual networks to be highly dynamic, reconfigurable, and adaptive to facilitate consumer-designed supply chains via online markets. Supply network of OFN as a collection of consumer-designed supply chains freely emerges on consumer demand and adapts to fulfil food orders effectively and efficiently.

When a supplier holds more contracts, which is high in degree centrality, it can play a central role as a coordinator by collecting orders from other suppliers (Kim et al., 2011). Such suppliers can align customer segments with innovative business strategies to achieve higher customer satisfaction. Consumers prefer suppliers with high in-degree centrality who receive from many other suppliers and act as food integrators (Kim et al., 2011). Such food suppliers create vast opportunities for consumers ordering a variety of food items, ranging from meat, fish, eggs, fruit, vegetables, wine, baked goods and grain under one shelter, and deciding the producers for each item from the available pool of suppliers attached to them. Then again, suppliers with high outdegree centrality act as food allocators by distributing their products to many other suppliers (Borgatti and Li, 2009; Kim et al. 2011). Other suppliers prefer to include high out-degree centrality suppliers into their supplier base since they are readily available to supply food. So, consumers also recognise the potential of high out-degree centrality suppliers to order items via high in-degree centrality suppliers. Since consumers are more likely to choose both high in-and out-degree 
suppliers to their food supply chains, these suppliers' sales probability increases over time. Hence, the following hypothesis is proposed:

Hypothesis 1: The higher the number of contracts that a supplier holds in an open contractual network, the higher it's sales probability will be in the supply network, over time.

Open contractual network of OFN connects suppliers online in multiple food and beverage industries in Australia. This network consists of geographically remote network clusters to satisfy regional consumers. These consumers, however, consider certain factors such as logis tics costs, reliability, flexibility, and delivery, when placing orders online (Pathak et al., 2007; Terjesen et al., 2011). Closeness centrality indicates how close a supplier is to all other suppliers in the network and it determines the supplier's geographic and conceptual proximity (Freeman, 1979). In this study, the highest scores indicate more closeness.

Closeness centrality represents the extent to which a food supplier can navigate freely across the network to access and deliver products promptly (Freeman, 1979; Kim et al., 2011). Suppliers with high closeness centrality have more freedom from others' influence and a high capacity for independent actions (Kim et al., 2011). Since these suppliers locate in the shortest path of the open contractual and supply networks of OFN, they can optimally balance supply and demand with lower inventory and operational costs (Borgatti and Li, 2009; Lee, Padmanabhan and Whang, 2004). If a consumer chooses to pick up products rather than delivery, the consumer can quickly cover the chosen food suppliers to collect the ordered items by following the shortest path through high closeness centrality suppliers. As such, consumers are more likely to order from these suppliers of the open contractual network. Hence, the following hypothesis is proposed:

Hypothesis 2: The quicker a supplier can reach all the other suppliers in the open contractual network, the higher it's sales probability will be in the supply network, over time. 


\section{Environmental Uncertainty Dimensions as Moderators: Dynamism, Munificence and}

\section{Complexity}

Dynamism refers to the level of environmental volatility or unpredictable change within an industry that intensifies uncertainty (Dess and Beard, 1984; Gligor, 2018). Dynamic environments commonly put high pressure on high-degree centrality suppliers. For instance, supermarket domination prevents regional farmers from supplying beyond the restricted quotas, and consequently, there will be product surpluses (National Association of Retail Grocers of Australia, 2007). Therefore, high degree centrality suppliers promote alternative sales platforms, such as OFN, in coordination with other suppliers. Eventually, these suppliers will have a significant impact on other suppliers' operational decisions and strategic behaviour (Kim et al., 2011; OFN, 2018). Suppliers continuously evolve, extracting regular patterns from random events to develop rules and strategies for their interrelationships within a CAS such as the networks of OFN (GellMann, 1994).

Dynamism inlays unanticipated fluctuations in both the open contractual and supply networks, and that leads to transitions in network patterns which in turn change the central positions of suppliers. In dynamic environments, suppliers with high degree centrality perceive leadership roles when coordinating other suppliers (Freeman, 1979; Kim et al., 2011). Suppliers with high indegree centrality can manage incoming resource flow from upstream suppliers (Kim et al., 2011). For instance, they can transform different food items into a value-added product, such as vegetable and fruit boxes, meat boxes, and beverage cartons. Also, suppliers with high out-degree centrality can manage demand flow by efficiently distributing ordered items to other suppliers. For instance, the food suppliers of OFN arrange a fortnight or weekly deliveries to schools and other community places, so the groups of consumers can pick up their ordered items there. Hence, in dynamic 
environments, consumers are more likely to order from high degree centrality suppliers that aggregate, distribute, and market food products, primarily sourced from local and regional producers. Hence, the following hypothesis is proposed:

Hypothesis 3: Higher dynamism leads to a stronger positive relationship between a supplier which holds a higher number of contracts in the open contractual network and its sales probability in the supply network, over time.

Dynamism adversely impacts the open contractual and supply networks, thereby weakening the shared supply chain strategies and suppliers' sales. Long average path lengths between suppliers in a network are detrimental to network's robustness against disruptions, while shorter average distances allow faster propagation of products and information (Nair and Vidal, 2011). Consumers favour high closeness centrality suppliers concerning logistics costs, but dynamic environments lower the product reliability, flexibility and responsiveness and, this may weaken customer loyalty.

When contractual and supply networks are adapting to dynamic environments, some ties and suppliers may exit from the shortest paths while new ties and suppliers may enter to the shortest paths and, hence, the closeness centrality of suppliers may decrease and consequently the sales. Suppliers advance regular supply network operations by selectively connecting to other wellconnected suppliers (Borgatti and Li, 2009). However, in dynamic environments, these suppliers are vulnerable to network disruptions, due to their greater dependence on dominant suppliers (Borgatti and Li, 2009; Nair and Vidal, 2011). Hence, dynamism lowers the positive association between the supplier's closeness centrality and its sales probability. This leads to the following hypothesis: 
Hypothesis 4: Higher dynamism leads to a weaker positive relationship between a supplier which can quickly reach all the other suppliers in the open contractual network and its sales probability in the supply network, over time.

Munificence is the resource abundance of the environment that support sustained growth of a firm and, thus, focuses on an industry's sales trend (Dess and Beard, 1984; Terjesen et al., 2011). According to transactions cost economics theory, asset specificity of suppliers causes their potential opportunistic behaviour in exchange relationships (Slater, 1997). Firms increase their risks by remaining in markets where resources are relatively scarce (Anderson and Tushman, 2001; Keats and Hitt, 1988). They need to expand their operations into new markets through diversification strategy that balances the overall risks and increases the sales performance (Dess and Beard, 1984; Keats and Hitt, 1988; Pagell and Krause, 2004).

Network structure, derived from the suppliers' compendium of ties, partially determines the opportunities and constraints to access valuable resources and information that would help suppliers sustain competitive advantage (Burt, 1992; Nahapiet and Ghoshal, 1998). Suppliers with high degree centrality can influence other extended suppliers either to compete or cooperate or both when developing value-added products (Bellamy et al., 2014; Kim et al., 2011; Wu and Choi, 2005). Since these suppliers can capture the potential transactional intensity and related risks of the open contractual network, they can influence the extended suppliers' operational scope. High degree centrality suppliers are willing to take the opportunities of high munificent environments to cater the various market demands. Consumers also prefer to order from such suppliers that could provide a large variety of products under one shelter and, hence, their sales probability is high in the supply network. Consequently, this following hypothesis is proposed: 
Hypothesis 5: Higher munificence leads to a stronger positive relationship between a supplier which holds a higher number of contracts in the open contractual network and its sales probability in the supply network, over time.

The OFN is more vital in munificent environments, as its primary purpose is to become an alternative platform for sustainable producers and food hubs to sell their surplus products to the consumers with remote access to fresh food, but it has spread into the other customer segments as well, such as the universities, food fairs, prisons, and hospitals. The food hubs evolve as an intermediary that provides open access to the small- and medium-sized producers and consumers, improving coordination, sustainability, and resilience of local food supply chain (Matson and Thayer, 2013). All these food suppliers commit to provide nutritious and organic products to their local community and to deliver on time by reconfiguring the open contractual and supply networks (Kurnia et al., 2017; Rose and Larsen 2015).

Suppliers with high closeness centrality deliver the products promptly to consumers, as they can quickly reach most of the other suppliers in the supply network (Freeman, 1979). Suppliers that are at a short distance from most other suppliers receive information and products sooner than the suppliers that are far away from most others (Borgatti and Li, 2009). The other suppliers also like to join the short food supply chains to get more sales, while consumers place more orders to the high closeness centrality suppliers to get the benefits of less operational and inventory costs (Lee et al., 2004). Therefore, in munificent environments, suppliers with high closeness centrality further increases their sales probability. Hence, the following hypothesis is proposed:

Hypothesis 6: Higher munificence leads to a stronger positive relationship between a supplier which can quickly reach all the other suppliers in the open contractual network and its sales probability in the supply network, over time. 
An industry's complexity implies by the number of firms and their composition regarding the size and perceived resources (Child, 1972; Dess and Beard, 1984). Low concentrated industries are highly complex and less monopolistic (Keats and Hitt, 1988). Suppliers may mask their competitive moves and are likely to engage in vigorous backbiting in complex environments (Porter, 2008). In contrast, highly-concentrated industries are less complicated and empower monopolistic firms to impose discipline and play a coordinative role in target markets (Azadegan et al., 2013; Keats and Hitt, 1988). However, any shift in complexity structure of industry influences government regulations, entry barriers, incentives to innovation, and product diversification (Azadegan et al., 2013; Gligor, 2018; Keats and Hitt, 1988).

In a complex business environment, a supplier needs to satisfy the environmental expectations placed on it with the available resources, capabilities, and products to remain operationally sustainable (Li et al., 2010). If suppliers are unable to leverage extensive information that can be accessed from other suppliers, they are likely to face legal consequences and weak performances (Pathak et al., 2007). A supplier enhances its ability by having more direct contacts with other suppliers in the open contractual network to absorb the external knowledge in response to increased information processing demands and open innovation. Hence, new suppliers also prefer connecting with high degree centrality suppliers of the open contractual network to attract consumers than connecting to isolated suppliers. Further, consumers mostly trust these suppliers in a market spoiled by choice with a large number of physical establishments. Eventually, the OFN producers that start with fewer connections transform into high degree centrality food hubs, in response to heterogeneous market demands. Hence, in complex environments, suppliers with high degree centrality further increase their sales probability, over time. This leads to the following hypothesis: 
Hypothesis 7: Higher complexity leads to a stronger positive relationship between a supplier which holds a higher number of contracts in the open contractual network and its sales probability in the supply network, over time.

In complex environments, various inputs and outputs create an array of possible supply network reconfigurations, based on shortest paths. Network reconfigurations motivate the coexistence of competition and cooperation among suppliers (Surana et al., 2005). In doing so, one of the main challenges is to facilitate the adaptive, flexible, and synchronised behaviours of suppliers driven by their motivations and environmental perspectives (Li et al., 2010). It is even more critical to find the strategic fit between the network structure and the collaboration patterns (functionality) (Li et al., 2010; Surana et al., 2005). Suppliers continuously change their relationships to increase their internal fit to the open contractual and supply networks and external fit to the environment (Choi et al., 2001; Park et al., 2018). However, they try to locate in shortest paths of networks to deliver a diverse product range.

Closeness centrality is an indication of the number of steps that a supplier's raw materials had to get through to the supplier (Borgatti and Li, 2009; Freeman, 1979). Since longer paths increase the operational costs and network disruptions, high closeness centrality suppliers are in relatively powerful positions to distribute a wide range of products, with shorter and more flexible delivery times. In complex environments, suppliers are likely to connect with high closeness centrality suppliers to reduce logistics costs and improve on-time delivery while consumers order more from them which in turn increase their sales probability. Hence, the following hypothesis is proposed:

Hypothesis 8: Higher complexity leads to a stronger positive relationship between a supplier which can quickly reach all the other suppliers in the open contractual network and its sales probability in the supply network, over time. 


\section{RESEARCH METHODOLOGY}

\section{Data and Operational Definitions}

This study identifies two types of directional networks that coexist in the OFN, these being the open contractual and supply networks. The two networks are CASs because many non-additively interacting suppliers organise themselves in an interdependent and networked manner (Choi et al., 2001; Holland, 2002). The open contractual network of OFN started in 2012 with 34 food suppliers and grew to $96,234,1033$, and 1876 , respectively, until 2016. The corresponding supply network started with 30 food suppliers and evolved to 71, 234, 395, and 503, respectively, along with the open contractual network's evolution. Table A1 and Table A2 in Appendix A indicate the percentage distribution of OFN suppliers by state and product group in sequence from 2012 to 2016. The network deals with 52 main product categories. The study used IBISworld industry reports from 2008 to 2016 to measure the environmental uncertainty dimensions. Since most of the suppliers supply multiple food items, the aggregate industry measures were calculated for these dimensions. The unit of analysis is the food supplier of the open contractual network of OFN. This study used SNA and panel logit regression modelling methods to test the hypotheses.

\section{Operational definitions of the Key Variables}

Degree centrality: In-degree centrality is the number of ties received by the supplier, and outdegree centrality is the number of ties initiated by the supplier (Borgatti, Everett and Freeman, 2002; Borgatti and Li, 2009; Freeman, 1979; Granovetter,1973; Kim et al., 2011). This study uses the log transformation of the sum of the in- and out-degree centralities to calculate supplier's degree centrality. 
Closeness centrality: Closeness centrality of a supplier is the reciprocal of farness, which is the sum of the lengths of the ties to every other supplier (Borgatti et al., 2002; Borgatti and Halgin, 2011; Borgatti and Li, 2009; Freeman, 1979; Granovetter, 1973; Kim et al., 2011; Kito et al., 2014). As an alternative, the reciprocals can be taken before summation than after. (Everett and Borgatti, 2010). In this study, closeness is the sum of the reciprocated distances, so that the infinite distances contribute to a value of zero (Borgatti et al., 2002; Everett and Borgatti, 2010). Since the open contractual network is directional, paths calculate separate measures for in- and out-closeness. So, the study first calculates the average of both in- and out-closeness centralities, and then obtain the $\log$ transformation to derive the closeness centrality measure.

Munificence: Munificence is the five-year average growth in industry sales revenue, and industry value added in which the supplier is involved in (Dess and Beard, 1984; Keats and Hitt, 1988; Gligor, 2018). Measures are in $\$$ millions. The basic equation is $y_{t}=b_{0}+b_{1} t+a t$ where $y$ is natural logarithms of sales revenue/industry value added, $t$ is year and $a$ is residual. Growth measure is the average of the antilog transformations of regression coefficients of the industry sales revenue and industry value added (Keats and Hitt, 1988; Gligor, 2018; Gligor et al., 2015). This study uses fiveyear data since it is the length of a typical planning horizon (Azadegan et al., 2013).

Dynamism: Dynamism is the five-year patterns of the instability of the environment (Keats and Hitt, 1988; Gligor, 2018). It is the average of the antilog transformations of the standard errors of each regression slopes (industry sales revenue and value added) measured for munificence (Eroglu and Hofer, 2014; Gligor, 2018; IBISworld, 2016).

Complexity: Complexity represents the breadth and variety of the industries' geographic markets where the supplier operates in (Bozarth et al., 2009; Child, 1972). This study uses five-year average growth of the number of physical establishments of the industries that the supplier operates in to calculate complexity measure (IBISworld, 2016; Keats and Hitt, 1988). The basic equation 
followed is $y_{t}=b_{0}+b_{1} t+a t$ where $y$ is natural logarithms of the number of physical establishments, $t$ is year and $a$ is residual (Gligor, 2018). So, the complexity measure is the antilog transformation of the regression coefficient. An establishment is a single physical location where a business operates (IBISworld, 2016).

Sales Probability: Sales probability is a binary variable. If a supplier generates sales in the supply network, it is 1; otherwise, it is 0, as per the convention followed in other studies (Beamon, 1999; Lee et al., 2004).

\section{Descriptive Statistics}

Table 1 provides descriptive statistics and the correlations between variables. A significant correlation exists between degree and closeness centralities because high degree centrality suppliers sometimes rapidly reach other suppliers in a geographically remote cluster. The correlations among the environmental uncertainty dimensions are attributable to their simultaneous occurrences. Correlations exist among the SCE and the environmental uncertainty dimensions because of the interplay between the open contractual network of OFN and its local environment. However, there is no multicollinearity problem in the models tested that include these variables and, hence, correlations are of no great concern.

Insert Table 1 about here

\section{RESULTS}

This study conducted the analysis in two steps, using SNA and panel logit regression model, respectively. SNA was carried out with the help of UCINET software to visualise the network evolutions from 2012 to 2016, as shown in Figure 2. These diagrams demonstrate how the open 
contractual and supply networks of OFN evolved within five years. These networks started and evolved in the state of Victoria within the first two years and then slowly spread into the other states from 2014 to 2016 . Volunteer consumer and food supplier associations mostly facilitate the collaboration of these geographically isolated network clusters that operate via OFN, while some food suppliers independently make online sales. This study used SNA to derive degree and closeness centrality measures of the independent variable, SCE.

The moderated panel logit regression method was used to test the hypotheses, given the dichotomous nature of the dependent variable, the supplier's sales probability in the supply network. The regression model is unbalanced because the number of suppliers of the open contractual network varies over time. Control variables, product type and state, do not vary significantly, over time, and the suppliers of OFN are a small representation of the Australian food suppliers in each category. Hence, this study used the random effects panel logit regression model for the analysis (Allison, 2009). This study used the 'xtlogit' function of STATA software for this analysis.

Due to the intrinsically nonlinear nature of the limited dependent variable models, such as the panel logit regression, explanatory variables' estimated coefficients are rarely used to infer the true nature of the relationship between the explanatory variable and the dependent variable (Wiersema and Bowen, 2009; Bowen, 2012). Therefore, this study used both the odd ratio and the marginal effect. The odd ratio is the estimated increase in the log odds of the dependent variable per unit increase, in the value of the independent variable. Marginal effect is the effect of a unit change in an explanatory variable on the dependent variable that varies with the values of all variables in the model (Bowen, 2012; Wiersema and Bowen, 2009).

Table 2 shows the results of the moderated panel logit regression. The first model includes the effect of the control variables on the supplier's sales probability. The second model additionally 
includes the independent variables, SCE dimensions of supplier's degree and closeness centralities. The third model adds the moderators of the environmental uncertainty dimensions. The fourth model includes the interaction terms, which are the product of each of the mean centred SCE and environmental uncertainty dimensions.

Results support six of the eight hypotheses. Since the odd ratios are greater than one, a supplier's degree and closeness centralities increase its sales probability over time by supporting hypotheses 1 and 2. In both highly dynamic and complex environments, the supplier's degree centrality increases its sales probability, as the odd ratios of these relationships are significantly higher than one by supporting hypotheses 3 and 7. In munificent environments, supplier's closeness centrality increases its sales probability, with an odd ratio greater than one by supporting hypothesis 4. However, in dynamic environments, the positive effect of supplier's closeness centrality on its sales probability diminishes. As the odd ratio of this relationship is less than one, this supports hypothesis 6.

The relationship between a supplier's degree centrality and its sales probability is not evident in munificent environments, and thereby this contradicts hypothesis 5 . This may be because when most of the food suppliers have product surpluses, they directly sell their products for lower prices, rather than selling through food hubs. Therefore, consumers may reach both food producers and hubs to get price advantages in munificent environments. Also, the relationship between a supplier's closeness centrality and its sales probability is absent in complex environments. Now and then, consumers chase after local brands when lots of choices are available in complex markets without concerning the logistics costs. Hence, hypothesis 8 is possibly not being supported.

Insert Figure 2 about here

Insert Table 2 about here 
This study uses graphical illustrations to further elaborate the hypotheses in the panel logit model, by examining the sign and statistical significance of marginal effect values of the explanatory variable over the values of all model variables (Wiersema and Bowen, 2009). In Figures 3,4,5,6,7 and 8, the blue colour, circle symbols indicate marginal effect values of the explanatory variable as recorded on the left axis, while the red colour, diamond symbols indicate the z-statistic values as recorded on the right axis. Figures 3 and 4 exhibit the direct effects of the degree and closeness centralities, respectively on supplier's sales probability. All marginal effect values are positive in Figures 3 and 4, as indicated by the sign of the coefficients of the second model. The marginal effect values of the degree centrality range from 0 to 0.68 while its $\mathrm{z}$-statistic values range from 0.34 to 12.16 . Figure 3 indicates that the marginal effect values above around 0.12 , exceed the $1.96 \mathrm{z}$-statistic reference line within the range of -3 to 3 of the sales probabilities. Rest of the marginal values in Figure 3 confirm that a supplier's degree centrality significantly increases its sales probability at $\mathrm{p}<.01$.

The marginal effect values of the closeness centrality range from 0 to 2.58 and its $\mathrm{z}$-statistic values range from 0.35 to 9.59 . Figure 4 indicates that the marginal effect values above around 0.5 , exceed the $1.96 \mathrm{z}$-statistic reference line within the approximate range of -3 to 3 of the sales probabilities. Remaining marginal values confirm that a supplier's closeness centrality significantly increases its sales probability at $p<.01$. The summary measures yield a marginal effect of 0.54 for the degree centrality, and 2.04 for the closeness centrality, at the means of all the variables of the third model with corresponding $\mathrm{z}$-statistics of 2.79 and 2.58 (at $\mathrm{p}<0.1$ ).

The results confirm that only dynamism and complexity positively moderate the relationship between a supplier's degree centrality and its sales probability. Figures 5 and 6 show that most of the marginal effect values of these interaction effects are between the $\mathrm{z}$ statistic 
reference lines of -1.96 and 1.96 . Hence, all the values confirm the significant interaction effects. Nonetheless, they mostly indicate positive moderations for the negative sales probability and negative moderations for the positive sales probability.

Dynamism negatively moderates the relationship between a supplier's closeness centrality and its sales probability, while munificence positively moderates that relationship. Figures 7 and 8 show that most of the marginal effect values of these interaction effects are between the $\mathrm{z}$ statistic reference lines of -1.96 and 1.96 . However, they mostly indicate negative moderations for the negative sales probability and positive moderations for the positive sales probability. For all four significant interaction effects, there is a turning point at zero sales probability. Hence, these graphs partially support the moderation hypotheses of 3, 4, 6, and 7 .

Insert Figure 3,4,5,6,7 and 8 about here

\section{Robustness}

This study performed a robustness test using a random effect panel logit regression model. The study replaced degree centrality by the eigenvector centrality and closeness centrality by the betweenness centrality. The selection of alternative variables is based on their likeness of representing a node's centrality in a network. For instance, eigenvector centrality is an extension of degree centrality while a node with high betweenness centrality is likely to have high closeness centrality as well (Bonacich and Lloyd, 2001; Borgatti and Li, 2009; Freeman, 1979). Consequently, the values of moderation effects are also changed by multiplying the eigenvector and betweenness centralities with respective environmental uncertainty dimensions. Results support four hypotheses out of the proposed eight. Robustness analysis empirically validates H2, $\mathrm{H} 3, \mathrm{H} 4$ and $\mathrm{H} 6$ corresponding to the original analysis. The original analysis supports $\mathrm{H} 1$ and $\mathrm{H} 7$, but not in the robustness analysis. The test suggests that the proposed conceptual model is robust. 


\section{Endogeneity}

This study performed a random effect panel tobit regression model as an endogeneity test. All the test results are significant. However, the test empirically validates only $\mathrm{H} 1, \mathrm{H} 2, \mathrm{H} 3, \mathrm{H} 4, \mathrm{H} 6$ and $\mathrm{H} 7$ because the sign of the H5 and $\mathrm{H} 8$ are opposite from the hypotheses suggestions. Therefore, tobit test confirms all the hypotheses supported by the original analysis. Overall, the conceptual model does not have endogeneity problem.

\section{DISCUSSION}

This study primarily investigates how the open contractual network derives the supply network in each order cycle, in response to the environmental uncertainty dimensions over time. The results reveal that the SCE, as informed by the SNA matrices of degree and closeness centralities, generally improves the supplier's sales probability in the supply network. Further, the study elucidates how the open contractual network interacts with the environmental uncertainty dimensions without any controller to increase the embedded supplier firm's performance.

Dynamism and complexity dimensions positively moderate the relationship between a supplier's degree centrality and its sales probability. Marginal effects confirm that these dimensions are positive moderators for the sales probabilities less than zero and become negative moderators for the sales probabilities greater than zero. Munificence positively moderates the relationship between a supplier's closeness centrality and its sales probability, but dynamism negatively moderates this relationship. However, the marginal effects indicate that these dimensions are negative moderators for the sales probabilities less than zero and become positive moderators for the sales probabilities greater than zero.

\section{Theoretical Contributions}


Existing literature offers minimal knowledge about online markets where the open contractual network derives the supply network. Consumers choose suppliers to their supply chains by considering factors such as SCE, suppliers' product profiles and shipping distances. SCE is an important factor because suppliers of the open contractual network earn sales, only if consumers place orders to them via online market. Therefore, this study first explores the effects of the SCE on the supplier's sales probability in the supply network, over time, an area that is mostly unexplored in the literature.

Further, the supply chain literature relies mostly on subjective measures to inform the embeddedness, because of difficulties in network data collection (Choi and Hong, 2008; Kim, 2014). Hence, this study uses the objective measures based on the SNA matrices of degree and closeness centralities to inform the SCE. The conflicting beliefs existed regarding the suppliers' embeddedness and performance relationship, as to whether it is non-linear or linear (Kim et al., 2011; Kim et al., 2015; Uzzi, 1996). This study addresses these contradicting beliefs and confirms that the SCE generally improves the supplier's sales probability in the supply network.

Literature mostly conceptualises the supply network as a CAS which coevolves with the environment but ignores the open contractual network (Choi et al., 2001; Surana et al., 2005; Park et al., 2018; Pathak et al., 2007). A few analytical studies model the supply network as a CAS to discuss the possible topologies (Pathak et al., 2007), evolutionary complexity (Li et al., 2010) and network robustness (Nair and Vidal, 2011), but with limited options. However, these studies are unclear about the system level interactions between the open contractual/supply network and environmental dimensions. Notably, the open contractual and supply networks coexist in online markets and simultaneously coevolve with the business environment. However, this has largely been neglected in prior literature. To address these knowledge gaps, this study first conceptualises the open contractual network as a CAS and empirically tests how it adapts to the environmental 
uncertainty dimensions to shape the suppliers' sales probability in the supply network. This study graphically unveils the simultaneous evolution, over five years, of the open contractual and supply networks of OFN.

To a more considerable extent, the supply network and environmental uncertainty literature have evolved independently, to explain the supplier's performance (Anderson and Tushman, 2001; Borgatti and Li, 2009; Gligor, 2018; Kim et al., 2015). They offer limited knowledge in merging these two constructs and how they interact to increase the supplier's sales probability. Therefore, this study offers a conceptual framework for empirical validation by integrating the CAS theory, SNA and the literature of environmental uncertainty, supply chain and performance. This study then reveals that the environmental uncertainty dimensions are more influential as moderators to the relationships between the centralities of SCE and the supplier's sales probability.

This study used the SNA technique to provide empirical evidence for the local optimisation behaviour of geographically remote network clusters embedded in both the open contractual and supply networks, when adapting to the environmental uncertainty (Choi et al., 2001; Holland, 1992, 2002). Existing literature scantly addressed this issue. The two networks first appear in 2012 as a hub and spoke system that shows the characteristics of a 'scale-free network', where food hubs played a leading role, and the attached food producers got small order quantities (Capaldo and Giannoccaro, 2015; Kim et al., 2015). In 2013, these networks evolved into a combination of different network patterns connected through structural holes revealing their nonlinear adaptation. A structural hole is where a supplier bridged a lack of connection between the other two suppliers (Burt, 1992). Additionally, the open contractual network consisted of the centralised network clusters, in which the food hub acts as a centralised inventory for food producers and a collection point for consumers (Capaldo and Giannoccaro, 2015), and the block diagonal clusters, where all the suppliers affect each other (Kim et al., 2015), but only the centralised pattern additionally 
emerges in the supply network. Both networks continued to show these network patterns until 2016. Figure 2 shows the graphical comparisons of the two networks to demonstrate that the supply network deviates from the open contractual network to cater to local demands, over time.

\section{Managerial Implications}

This study discusses a hybrid business model that was created as an online marketplace to sell suppliers' product surpluses to consumers who need quality, inexpensive products. With technology advancements, supplier associations can alternatively find online markets, such as the OFN, to reach the consumers directly. Also, consumers hold benefits, such as knowing where their products are coming from and cost savings by eliminating intermediaries in supply chains. In this hybrid business model, the supply network is the collection of consumer designed supply chains by choosing suppliers of the open contractual network. Therefore, supply network is a derivative of the open contractual network. These online markets challenge the inadequacies in traditional supply networks that keep raw material suppliers apart from consumers. This business model is not only for perishable supply networks, but it is consistent with any other types of product networks that operate via online.

This study mainly recommends suppliers embedded in a big network to make suitable subnetwork arrangements to cater the local consumers' interests in the presence of environmental uncertainty dimensions of dynamism, munificence, and complexity. The geographically remote network clusters adapt to different forms of network patterns, such as scale-free, centralised, and block diagonal, or a combination of these, to achieve the local opportunities. At the interface of network evolution, these small clusters change from one pattern to another, and consequently, suppliers change their centralities of the network embeddedness. Consumers are more likely to 
make orders to the suppliers that hold a higher number of contracts or quickly reach all the other suppliers in the open contractual network.

Internet-enabled, locally-efficient, open-contractual and supply networks operate simultaneously alongside the traditional material networks to overcome business environmental challenges. The environmental uncertainty dimensions interact with the open contractual network to shape the supplier's sales probability in the supply network. So, the suppliers have to change their centralities in the open contractual network to adapt to the environmental uncertainties and, hence, to grab market opportunities. These interactions are effective strategic means of transferring resources, knowledge, and technology across the network that ensure the supplier's sales probability. Suppliers who adapt to these interactions will get a competitive advantage to stay operationally sustainable in their target markets and approach new markets. Having proper awareness of the interaction effects can help prevent unexpected disruptions to the supplier and consumer relationships and mitigate the negative impact on sales improvements.

\section{CONCLUSION AND FUTURE RESEARCH}

This study integrates CAS theory, SNA, and literature of environmental uncertainty, supply chain and performance to explore the relationships among the environmental uncertainty, SCE and supplier's sales probability. Existing literature mostly conceptualises the supply network as a CAS but not the open contractual network. Hence, this study first conceptualises the open contractual network as a CAS and explains how it leads to freely emerging supply network without any supplier's controlling influence.

Although the open contractual and supply networks coexist in an online market, the open contractual network derives the supply network in each order cycle purely based on consumer demands. Consumers mainly consider the aspects of SCE such as supplier's product profiles and 
shipping distances before placing orders to a supplier. However, the SCE, how a supplier connected to other suppliers in the open contractual network received less attention in the literature. Also, the prior studies mostly used the subjective measures to inform the concept of embeddedness because of complications in network data collection, although SNA metrics are now widely available to objectively measure the embeddedness (Choi and Kim, 2008; Kim, 2014; Uzzi, 1996). Hence, this study explores the effects of the SCE, as informed by the degree and closeness centralities on the supplier's sales probability in the supply network.

The literature has taken opposite views on examining the effects of embeddedness on performance, including nonlinear and linear relationships (Kim, 2014; Kim et al., 2011; Kim et al., 2015; Uzzi, 1996). This study addresses these opposite views by confirming that the SCE as informed by degree and closeness centralities commonly increases the supplier's sales probability, over time in research contexts where the supply network is a derivative of the open contractual network. This study graphically unveils the simultaneous co-evolution of the open contractual and supply networks over five years to adapt to the environmental uncertainty dimensions of dynamism, munificence and complexity. Geographically remote network clusters connect through structural holes in the big network and evolve into different network patterns over time. The open contractual and supply networks exhibit a local optimisation behaviour of a CAS because the network clusters change their patterns to cater the local opportunities than the global optimum of the entire network.

This study then discloses that the environmental uncertainty dimensions are more influential as moderators to the SCE and the supplier's sales probability relationship than their direct effects. In dynamic and complex environments, a supplier's degree centrality increases its sales probability. In munificent environments, a supplier's closeness centrality increases its sales probability, while dynamism lowers this positive relationship. Despite that, marginal effect 
diagrams demonstrate that moderators change the sign (positive or negative) of their moderation effects for the same relationship at the zero predicted sales probability. This study offers a more rigorous and scientific analysis, elucidating how to foster the CAS and SNA views of the open contractual network to develop the supply network and increase the embedded suppliers' sales probability.

While this study offers many useful insights, it has few limitations that future research can address. there are opportunities to design a simulation-based study to generate possible arrays of supply network topologies that could derive from the open contractual network. This study explored an Australian-based local network. Future research could replicate this study in other contexts to complement the findings of this study.

\section{REFERENCES}

Allison, P. D. 2009. Fixed effects regression models. SAGE publications.

Anderson, P. and Tushman, M. L. 2001. Organizational environments and industry exit: The effects of uncertainty, munificence and complexity. Industrial and Corporate Change, 10(3): 675-711.

Azadegan, A., Patel, P. C., Zangoueinezhad, A. and Linderman, K. 2013. The effect of environmental complexity and environmental dynamism on lean practices. Journal of Operations Management, 31(4): 193-212.

Beamon, B. M. 1999. Measuring supply chain performance. International Journal of Operations \& Production Management, 19(3): 275-292.

Bellamy, M. A., Ghosh, S. and Hora, M. 2014. The influence of supply network structure on firm innovation. Journal of Operations Management, 32(6): 357-373.

Bonacich, P. and Lloyd, P. 2001. Eigenvector-like measures of centrality for asymmetric relations. Social Networks, 23(3): 191-201.

Borgatti, S. P., Everett, M. G. and Freeman, L. C. 2002. Ucinet for Windows: Software for social network analysis.

Borgatti, S. P. and Halgin, D. S. 2011. On network theory. Organization Science, 22(5): 11681181.

Borgatti, S. P. and Li, X. U. N. 2009. On social network analysis in a supply chain context. Journal of Supply Chain Management, 45(2): 5-22.

Bowen, H. P. 2012. Testing moderating hypotheses in limited dependent variable and other nonlinear models: Secondary versus total interactions. Journal of Management, 38(3): 860-889. 
Burt, R. S. 1992. Structural holes: The social structure of competition. Harvard University Press. Capaldo, A. and Giannoccaro, I. 2015. Interdependence and network-level trust in supply chain networks: A computational study. Industrial Marketing Management, 44: 180-195.

Child, J. 1972. Organization structure, environment and performance: The role of strategic choice. Sociology, 6(1): 1-22.

Choi, T. Y., Dooley, K. J. and Rungtusanatham, M. 2001. Supply networks and complex adaptive systems: Control versus emergence. Journal of Operations Management, 19(3): 351-366.

Choi, T. Y. and Hong, Y. 2002. Unveiling the structure of supply networks: Case studies in Honda, Acura, and Daimler Chrysler. Journal of Operations Management, 20(5): 469-493.

Choi, T. Y. and Kim, Y. 2008. Structural embeddedness and supplier management: A network perspective. Journal of Supply Chain Management, 44(4): 5-13.

Eroglu, C. and Hofer, C. 2014. The effect of environmental dynamism on returns to inventory leanness. Journal of Operations Management, 32(6): 347-356.

Everett, M. G. and Borgatti, S. P. 2010. Induced, endogenous and exogenous centrality. Social Networks, 32(4): 339-344.

Freeman, L. C. 1979. Centrality in social networks, conceptual clarification. Social Networks, 1(3): 215-239.

Gell-Mann, M. 1994. Complex adaptive systems in Cowan, G.A., Pines, D. and Meltzers, D. (eds.), Complexity: Metaphors, Models and Reality, 17-45.

Gligor, D. 2018. Performance implications of the fit between suppliers' flexibility and their customers' expected flexibility: A dyadic examination, Journal of Operations Management, 58(1): 73-85.

Gligor, D. M., Esmark, C. L. and Holcomb, M. C. 2015. Performance outcomes of supply chain agility: when should you be agile?. Journal of Operations Management, 33(1): 71-82.

Granovetter, M. 1973 The strength of weak ties. American Journal of Socialogy, 78(6): 13601380.

Holland, J. H. 1992. Daedalus: A new era in computation (complex adaptive systems). Journal of the American Academy of Arts and Sciences, 121(1): 17-30.

Holland, J. H. 2002. Complex adaptive systems and spontaneous emergence' in Curzio, A.Q. and Fortis, P. M. (eds.), Complexity and Industrial Clusters Dynamics and Models in Theory and Practice, Physica-Verlag HD, 25-34.

IBISworld 2016. Australia Industry Reports (ANZSIC). Available: http://clients1.ibisworld.com.au.ezp.lib.unimelb.edu.au/reports/au/industry/home.aspx

Keats, B. and Hitt, M. 1988. A causal model of linkages among environmental dimensions, macro organizational characteristics and performance. Academy of Management Journal, 31(3): 570-598.

Kim, D. Y. 2014. Understanding supplier structural embeddedness: A social network perspective. Journal of Operations Management, 32(5): 219-231.

Kim, Y., Chen, Y.S. and Linderman, K. 2015. Supply network disruption and resilience: A network structural perspective. Journal of Operations Management, 33(1): 43-59.

Kim, Y., Choi, Y. T., Yan, T. and Dooley, K. 2011. Structural investigation of supply networks: A social network analysis approach. Journal of Operations Management, 29(3): 194-211. 
Kito, T., Brintrup, A. and New, S. 2014. The Structure of the Toyota supply network: An empirical analysis. Working paper. University of Oxford Report, Internal Saïd Business School.

Kurnia, S., Rahim, M.M., Hill, S., Larsen, K., Braun, P., Samson, D. and Singh, P.J. 2017. Supporting Local Food Supply Chain Players with Open Food Network in Social Inclusion and Usability of ICT-Enabled Digital Services. Routledge, Taylor and Francis Group, New York and London.

Lee, H. L., Padmanabhan, V. and Whang, S. 2004. Information distortion in a supply chain: the bullwhip effect. Management Science, 50(12): 1875-1886.

Li, G., Yang, H., Sun, L., Ji, P. and Feng, L. 2010. The evolutionary complexity of complex adaptive supply networks: A simulation and case study. International Journal of Production Economics, 124(2): 310-330.

Matson, J. and Thayer, J. 2016. The role of food hubs in food supply chains. Journal of Agriculture, Food Systems, and Community Development, 3(4): 43-47.

Nahapiet, J. and Ghoshal, S. 1998. Social capital, intellectual capital, and the organizational advantage. Academy of Management Review, 23(2): 242-266.

Nair, A. and Vidal, J. M. 2011. Supply network topology and robustness against disruptions-an investigation using multi-agent model. International Journal of Production Research, 49(5): 1391-1404.

Nair, A., Yan, T., Ro, Y. K., Oke, A., Chiles, T. H. and Lee, S. Y. 2016. How environmental innovations emerge and proliferate in supply networks: A complex adaptive systems perspective. Journal of Supply Chain Management, 52(2): 66-86.

National Association of Retail Grocers of Australia. 2007. The economic contribution of small to medium-sized grocery retailers to the Australian economy, with a particular focus on Western Australia, National Association of Retail Grocers of Australia Pty Ltd.

Open Food Network. 2018. Available: https://openfoodnetwork.org/

Pagell, M. and Krause, D. R. 2004. Re-exploring the relationship between flexibility and the external environment. Journal of Operations Management, 21(6): 629-649.

Park, H., Bellamy, M. A. and Basole, R. C. 2018. Structural anatomy and evolution of supply chain alliance networks: A multi-method approach. Journal of Operations Management, 63(1): 79-96.

Pathak, S. D., Day, J. M., Nair, A., Sawaya, W. J. and Kristal, M. M. 2007. Complexity and adaptivity in supply networks: Building supply network theory using a complex adaptive systems perspective. Decision Sciences, 38(4): 547-580.

Pathak, S. D., Dilts, D. M. and Biswas, G. 2007. On the evolutionary dynamics of supply network topologies. IEEE Transactions on Engineering Management, 54(4): 662-672.

Pathak, S. D., Wu, Z. and Johnston, D. 2014. Toward a structural view of co-opetition in supply networks. Journal of Operations Management, 32(5): 254-267.

Porter, M. E. 2008. Competitive advantage: Creating and sustaining superior performance, Simon and Schuster.

Rose, N. and Larsen, K. 2015. Economic benefits of 'creative food economies': Evidence, case studies and actions for Southern Melbourne. 
Slater, S. F. 1997. Developing a customer value-based theory of the firm. Journal of the Academy of Marketing Science, 25(2): 162-167.

StataCorp. 2017. Stata Statistical Software. Release 15.

Surana, A., Kumara, S., Greaves, M. and Raghavan, U. N. 2005. Supply-chain networks: A complex adaptive systems perspective. International Journal of Production Research, 43(20): 4235-4265.

Terjesen, S., Patel, P. C. and Covin, J. G. 2011. Alliance diversity, environmental context and the value of manufacturing capabilities among new high technology ventures. Journal of Operations Management, 29(1-2): 105-115.

Wiersema, M. F. and Bowen, H. P. 2009. The use of limited dependent variable techniques in strategy research: Issues and methods. Strategic Management Journal, 30(6): 679-692.

Wu, Z. and Choi, T. Y. 2005. Supplier-supplier relationships in the buyer-supplier triad: Building theories from eight case studies. Journal of Operations Management, 24(1): 27-52.

\section{APPENDIX A}

Table A1: Percentage distribution of the OFN suppliers by state

\begin{tabular}{|l|l|l|l|l|l|}
\hline State & 2012 & 2013 & 2014 & 2015 & 2016 \\
\hline Victoria & $82 \%$ & $66 \%$ & $77 \%$ & $69 \%$ & $72 \%$ \\
\hline New South Wales & $9 \%$ & $20 \%$ & $12 \%$ & $13 \%$ & $11 \%$ \\
\hline Northern Territory & $0 \%$ & $2 \%$ & $0 \%$ & $0 \%$ & $0 \%$ \\
\hline Queensland & $0 \%$ & $6 \%$ & $6 \%$ & $10 \%$ & $10 \%$ \\
\hline Australian Capital Territory & $3 \%$ & $1 \%$ & $1 \%$ & $1 \%$ & $1 \%$ \\
\hline Tasmania & $3 \%$ & $2 \%$ & $1 \%$ & $4 \%$ & $3 \%$ \\
\hline South Australia & $3 \%$ & $2 \%$ & $2 \%$ & $2 \%$ & $2 \%$ \\
\hline Western Australia & $0 \%$ & $1 \%$ & $1 \%$ & $1 \%$ & $2 \%$ \\
\hline
\end{tabular}

Table A2: Percentage distribution of the OFN suppliers by product group

\begin{tabular}{|l|l|l|l|l|l|}
\hline Product Group & 2012 & 2013 & 2014 & 2015 & 2016 \\
\hline Bakery & $3 \%$ & $0 \%$ & $2 \%$ & $3 \%$ & $2 \%$ \\
\hline Café, catering, restaurants and meals & $0 \%$ & $1 \%$ & $0 \%$ & $2 \%$ & $6 \%$ \\
\hline Meat, fish, cheese and milk & $9 \%$ & $13 \%$ & $19 \%$ & $30 \%$ & $21 \%$ \\
\hline $\begin{array}{l}\text { Fruit, vegetables, nuts, preserves, herbs, garlic, } \\
\text { honey, horticulture, drinks and mushrooms }\end{array}$ & $38 \%$ & $53 \%$ & $66 \%$ & $49 \%$ & $45 \%$ \\
\hline Market & $9 \%$ & $19 \%$ & $2 \%$ & $5 \%$ & $17 \%$ \\
\hline Oil and olive & $15 \%$ & $3 \%$ & $3 \%$ & $3 \%$ & $2 \%$ \\
\hline Pulses and grain, rice and flour & $15 \%$ & $6 \%$ & $4 \%$ & $3 \%$ & $2 \%$ \\
\hline Wine, beer, cider and liquor & $9 \%$ & $4 \%$ & $2 \%$ & $5 \%$ & $3 \%$ \\
\hline Other & $3 \%$ & $1 \%$ & $2 \%$ & $1 \%$ & $1 \%$ \\
\hline
\end{tabular}




\section{LIST OF FIGURES}

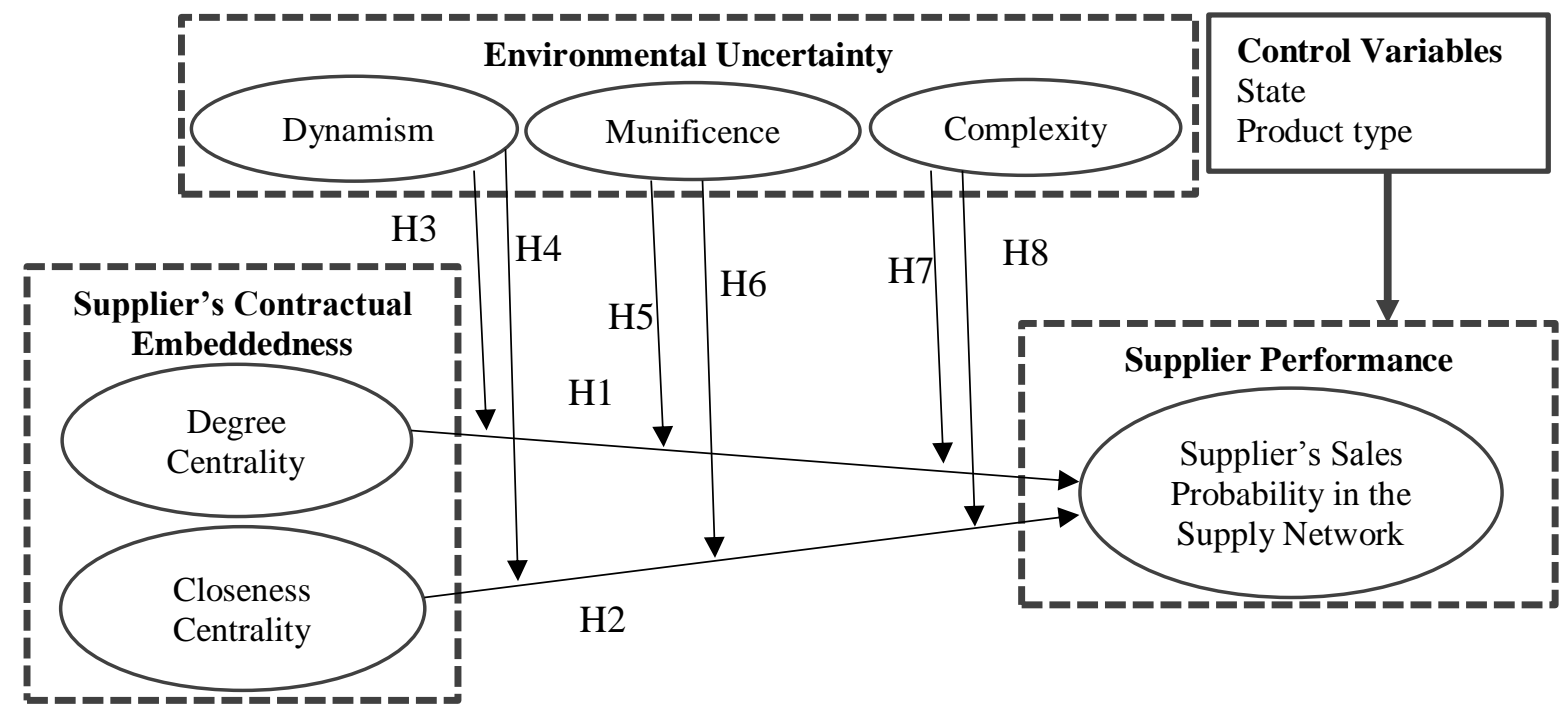

Figure 1: Conceptual model

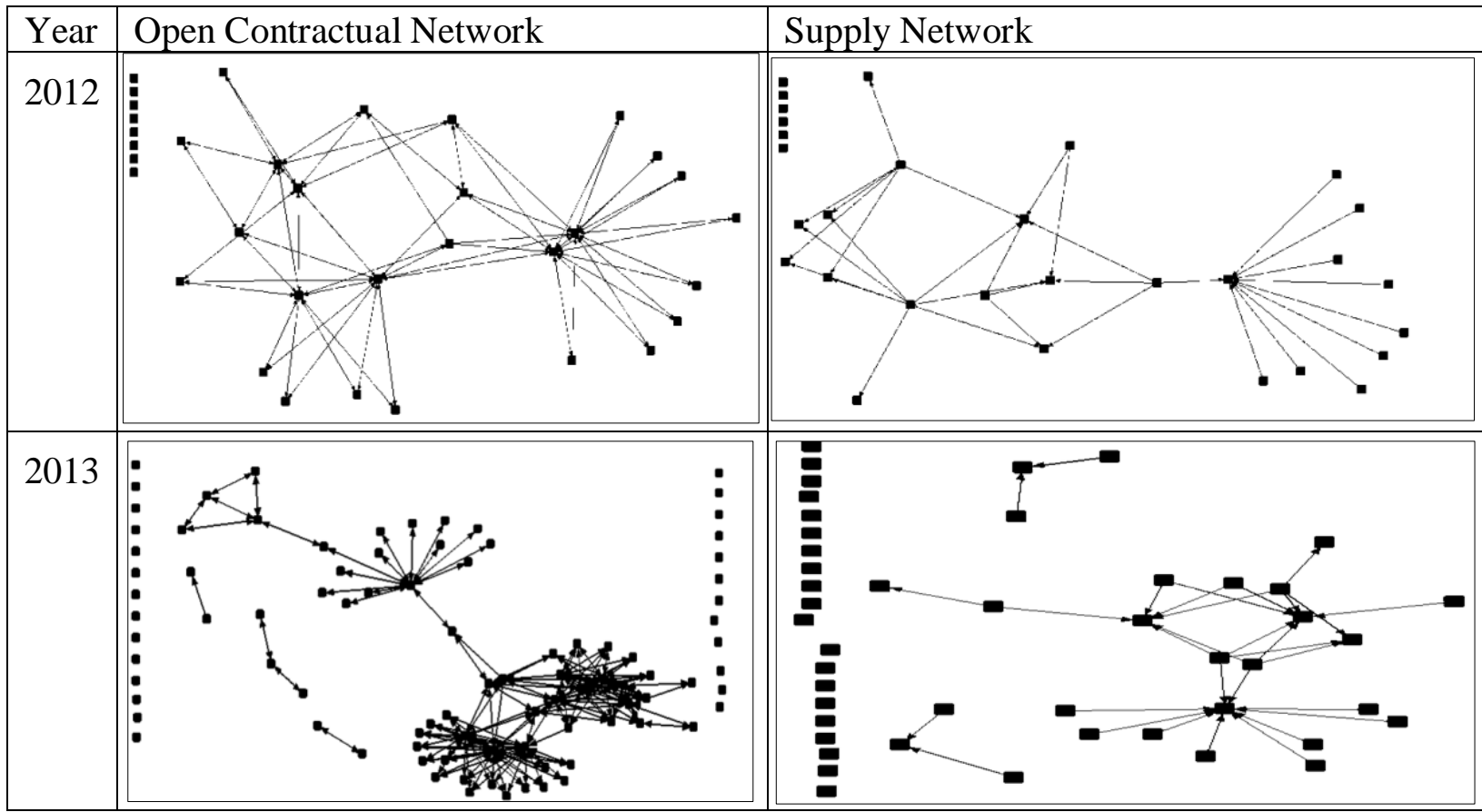




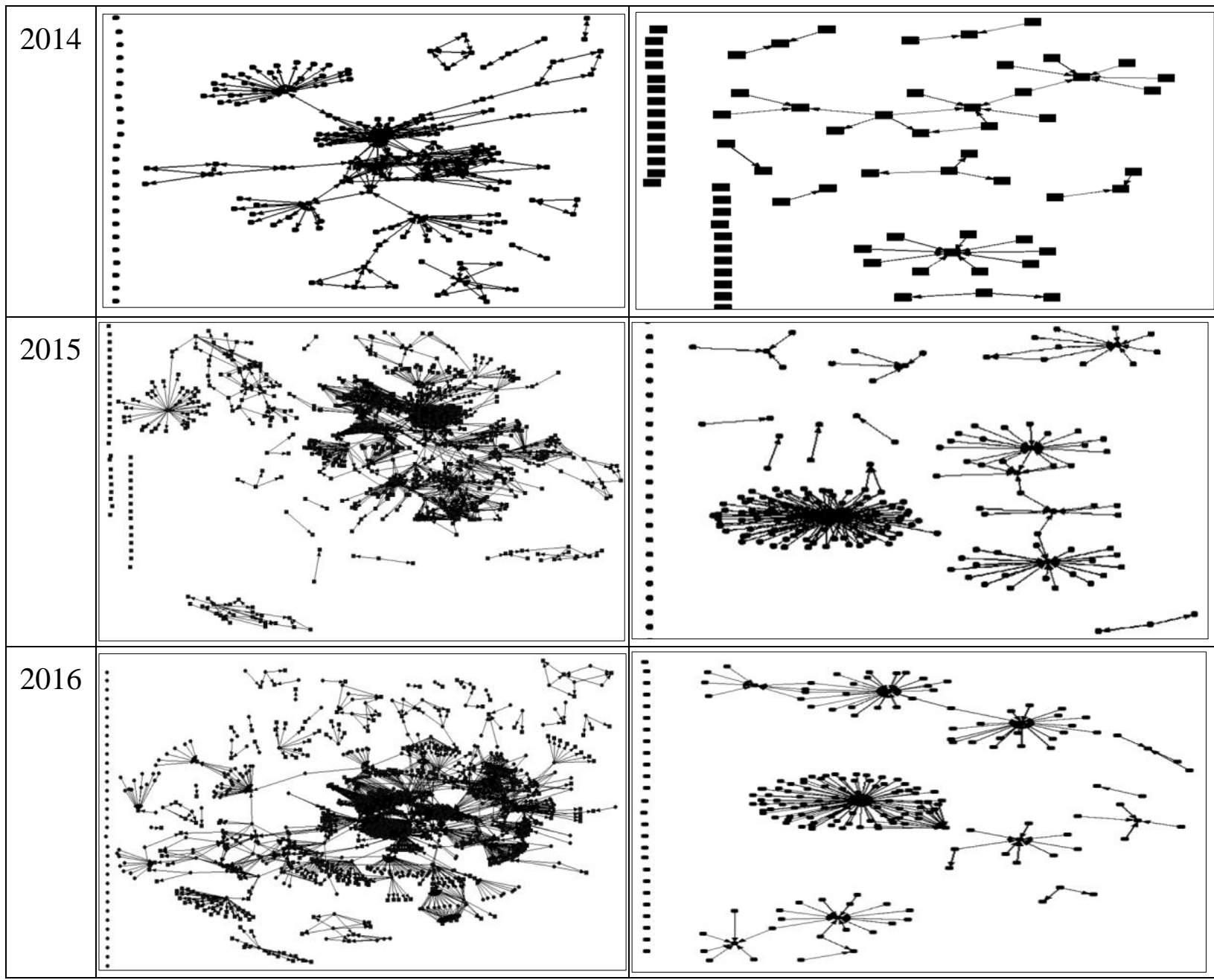

Figure 2: Open contractual and real supply network evolutions from 2012 to 2016

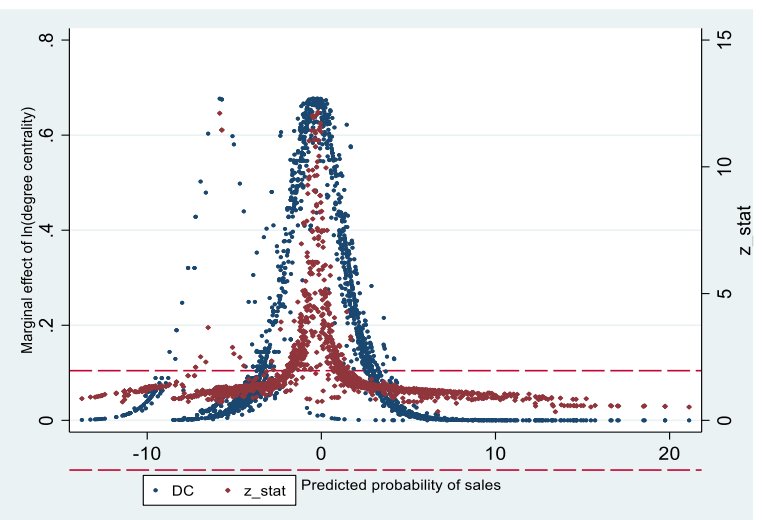

Figure 3: Degree centrality

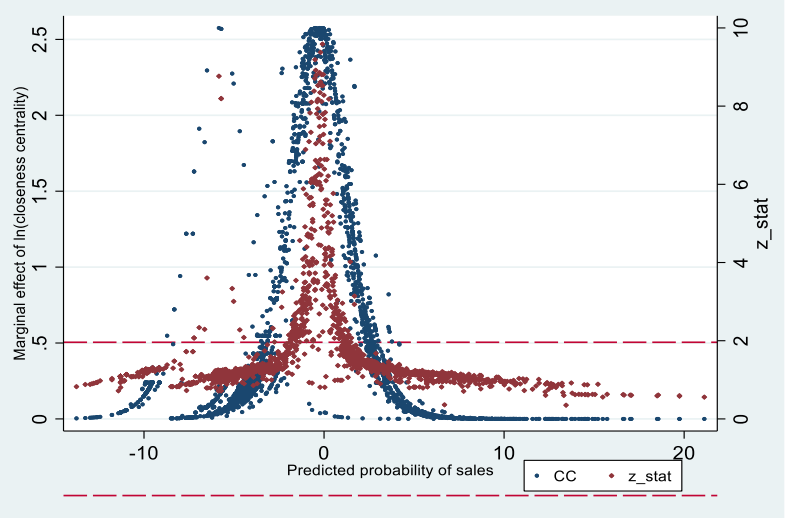

Figure 4: Closeness centrality 


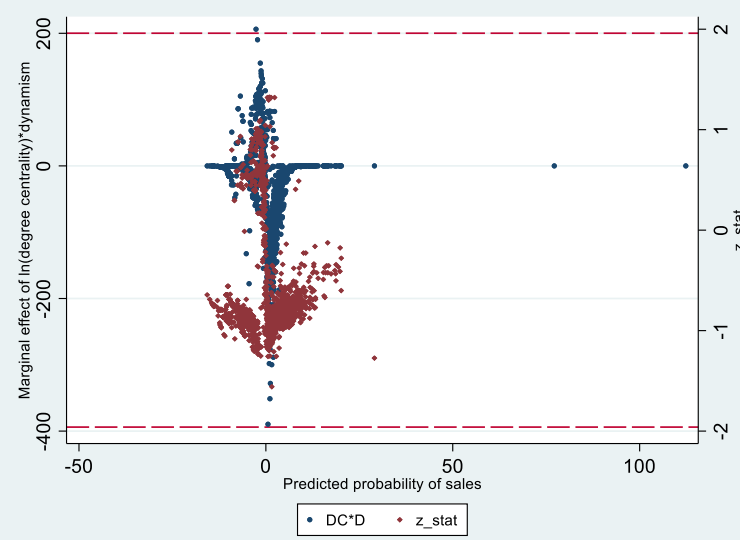

Figure 5: Degree centrality and dynamism

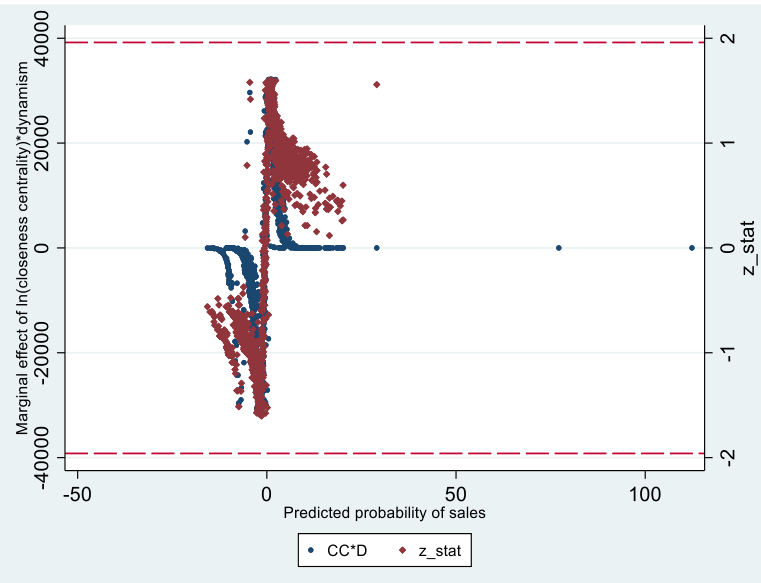

Figure 7: Closeness centrality and dynamism

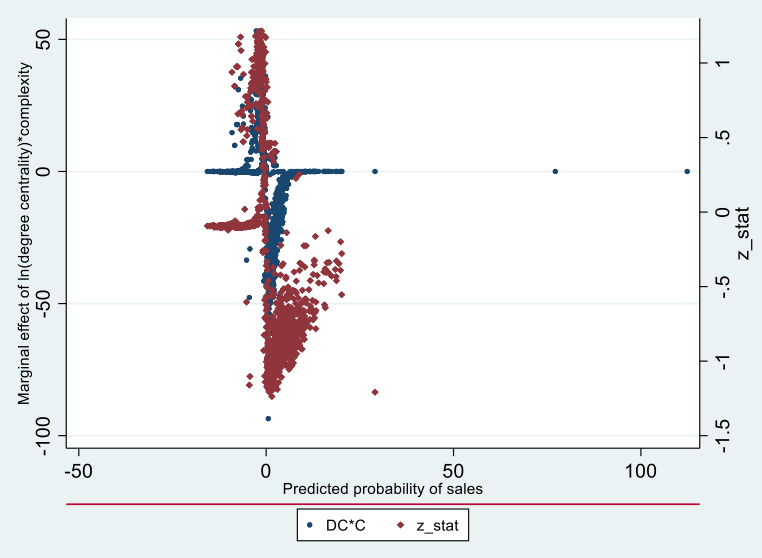

Figure 6: Degree centrality and complexity

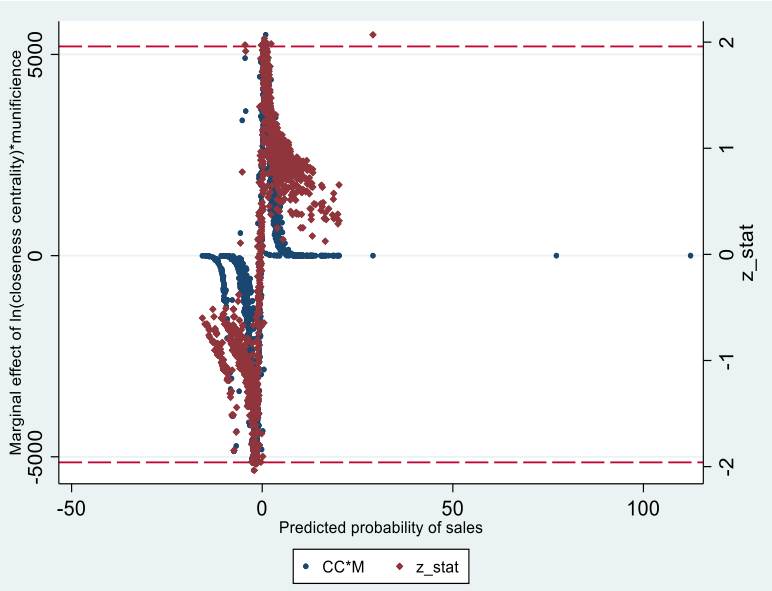

Figure 8: Closeness centrality and munificence

\section{LIST OF TABLES}

Table 1: Descriptive statistics and correlations

\begin{tabular}{|l|l|l|l|l|l|l|l|l|l|l|}
\hline Variable & Mean & $\begin{array}{l}\text { Standard } \\
\text { Deviation }\end{array}$ & Minimum & Maximum & 1 & 2 & 3 & 4 & 5 & 6 \\
\hline $\begin{array}{l}\text { 1.Degree } \\
\text { Centrality }\end{array}$ & 0.78 & 1.07 & 0.00 & 5.81 & 1.00 & & & & & \\
\hline $\begin{array}{l}\text { 2.Closeness } \\
\text { Centrality }\end{array}$ & -2.41 & 0.18 & -2.63 & -0.85 & $0.48^{*}$ & 1.00 & & & & \\
\hline 3.Dynamism & 1.01 & 0.01 & 1.00 & 1.12 & 0.01 & $0.10^{*}$ & 1.00 & & & \\
\hline 4.Munificence & 1.02 & 0.04 & 0.85 & 1.34 & $-0.09^{*}$ & $-0.07^{*}$ & $0.09^{*}$ & 1.00 & & \\
\hline 5.Complexity & 0.99 & 0.03 & 0.74 & 1.36 & $-0.07^{*}$ & $-0.05^{*}$ & $-0.14^{*}$ & $0.56^{*}$ & 1.00 & \\
\hline $\begin{array}{l}\text { 6.Sales } \\
\text { Probability }\end{array}$ & 0.37 & 0.48 & 0.00 & 1.00 & $0.63^{*}$ & $0.49^{*}$ & 0.02 & $-0.14^{*}$ & $-0.10^{*}$ & 1.00 \\
\hline
\end{tabular}

$* \mathrm{p}<0.01$ 
Table 2: Unbalanced panel logit regression results

\begin{tabular}{|c|c|c|c|c|c|c|c|c|c|c|c|c|c|}
\hline Model & Mode & & & Mode & & & Model & & & Model 4 & & & Hypothesis \\
\hline Sales & $\beta$ & $\mathrm{Z}$ & Odd ratio & $\beta$ & $\mathrm{z}$ & Odd ratio & $\beta$ & $\mathrm{z}$ & Odd ratio & $\beta$ & $\mathrm{z}$ & Odd ratio & \\
\hline Constant & -3.50 & $-3.36^{*}$ & 0.03 & 24.34 & $3.63^{*}$ & $3.72 \times 10^{10}$ & 56.02 & $4.30 *$ & $2.13 \times 10^{24}$ & 70.25 & $4.41 *$ & $3.24 \times 10^{30}$ & \\
\hline State & Yes & Yes & Yes & Yes & Yes & Yes & Yes & Yes & Yes & Yes & Yes & Yes & \\
\hline Product type & Yes & Yes & Yes & Yes & Yes & Yes & Yes & Yes & Yes & Yes & Yes & Yes & \\
\hline Degree centrality & & & & 2.31 & $7.56^{*}$ & 10.07 & 2.71 & $6.87 *$ & 14.99 & 2.81 & $6.26^{*}$ & 16.66 & H1: Yes \\
\hline Closeness centrality & & & & 11.09 & $4.20^{*}$ & 65241.54 & 10.30 & $3.86^{*}$ & 29794.79 & 14.51 & $4.00 *$ & 1994342 & H2: Yes \\
\hline Dynamism & & & & & & & -10.14 & -1.12 & $3.93 \times 10-5$ & -17.84 & $-1.48 * * *$ & $1.78 \times 10^{-08}$ & \\
\hline Munificence & & & & & & & -19.83 & $-4.66^{*}$ & $2.44 \times 10^{-9}$ & -18.39 & $-3.32 *$ & $1.03 \times 10^{-08}$ & \\
\hline Complexity & & & & & & & -3.83 & -0.63 & 0.02 & -1.46 & -0.18 & 0.23 & \\
\hline $\begin{array}{l}\text { Degree centrality } \\
* \text { Dynamism }\end{array}$ & & & & & & & & & & 39.26 & $2.16^{* *}$ & $1.12 \times 10^{17}$ & H3: Yes \\
\hline $\begin{array}{l}\text { Closeness centrality } \\
* \text { Dynamism }\end{array}$ & & & & & & & & & & -367.06 & $-2.55^{*}$ & $3.90 \times 10^{-160}$ & H4: Yes \\
\hline $\begin{array}{l}\text { Degree centrality } \\
* \text { Munificence }\end{array}$ & & & & & & & & & & -4.83 & -0.87 & 0.01 & H5: No \\
\hline $\begin{array}{l}\text { Closeness centrality } \\
* \text { Munificence }\end{array}$ & & & & & & & & & & 132.94 & $2.43^{* *}$ & $5.41 \times 10^{57}$ & H6: Yes \\
\hline $\begin{array}{l}\text { Degree centrality } \\
* \text { Complexity }\end{array}$ & & & & & & & & & & 17.30 & $1.48 * * *$ & $3.25 \times 10^{07}$ & H7: Yes \\
\hline $\begin{array}{l}\text { Closeness centrality } \\
* \text { Complexity }\end{array}$ & & & & & & & & & & 75.06 & 0.54 & $3.96 \times 10^{32}$ & H8: No \\
\hline Wald chi2 & \multicolumn{3}{|c|}{$21.16^{* * *}$} & \multicolumn{3}{|c|}{$228.97^{*}$} & \multicolumn{3}{|c|}{$201.57 *$} & \multicolumn{3}{|l|}{ 189.70* } & \\
\hline $\begin{array}{l}\text { Log } \\
\text { pseudolikelihood }\end{array}$ & \multicolumn{3}{|c|}{-1384.86} & \multicolumn{3}{|c|}{-1060.06} & \multicolumn{3}{|c|}{-1038.56} & \multicolumn{3}{|c|}{-1011.51} & \\
\hline
\end{tabular}

Number of observations $=3273$, Number of groups $=1876$, Observation per group: minimum $=1$, average $=1.7$, maximum $=5$ and $\mathrm{p}<0.01$ *

$\mathrm{p}<0.05^{* *}$

$\mathrm{p}<0.1 * * *$ 